\title{
Avaliação da estrutura de logística reversa das principais operadoras de celulares brasileiras sob a ótica dos consumidores e avaliação dos websites
}

RESUMO

Ricardo Henrique Moraes Santos ricardo.henrique092@gmail.com Universidade de Brasília (UnB), Brasília Distrito Federal, Brasil

Patricia Guarnieri profpatriciaunb@gmail.com

profpatriciaunb@gmividade de Brasília (UnB), Brasília Universidade de Bras
Distrito Federal, Brasil
Os elevados índices de consumo de aparelhos celulares têm aumentado a geração de resíduos no Brasil e no mundo. Diante desse cenário, a Logística Reversa e a Política Nacional de Resíduos Sólidos - PNRS emergem como possíveis soluções que atuam na redução dos impactos gerados por esse processo. Entretanto, a simples existência de tais soluções não garante os resultados almejados, sendo necessário o comprometimento de todos os atores envolvidos, sejam esses públicos, privados ou individuais. Buscou-se, portanto, avaliar as redes de logística reversa implementadas pelas operadoras de telefonia móvel no Brasil sob a ótica dos consumidores e avaliação de seus websites. Realizou-se uma pesquisa aplicada, descritiva e quali-quantitativa, cujo procedimento técnico foram o survey e a análise documental. A coleta de dados pautou-se na aplicação de um questionário com perguntas fechadas em uma amostra de 596 consumidores e também de um codificador adaptado para a análise dos websites das quatro principais operadoras de celular no Brasil. Os resultados obtidos no que tange à estruturação da logística reversa apresentou resultados considerados insatisfatórios, tanto sob a ótica do consumidor quanto pelo levantamento realizado em seus websites. A participação dos atores, com base na responsabilidade compartilhada, preconizada pela PNRS é premente para a efetiva implementação da logística reversa.

PALAVRAS-CHAVE: Logística reversa. Política Nacional de Resíduos Sólidos. Resíduos eletroeletrônicos. 


\section{INTRODUÇÃO}

Tendo em vista os elevados níveis de produção e consumo, surge o grave problema dos resíduos sólidos e, considerando-se que o modelo de produção adotado preocupa-se apenas com a fase inicial do processo, não dando a devida importância às questões do pós-consumo, é premente o surgimento de soluções. Hoje, segundo a Organização Mundial da Saúde - OMS a geração de resíduos no planeta gira em torno de $0,5 \mathrm{~kg} /$ habitante/dia, ou 3 bilhões de quilos de resíduos por dia (MMA - Ministério do Meio Ambiente, 2017).

No Brasil, o volume de resíduos gerado é de aproximadamente $220 \mathrm{~kg}$ por habitante ao ano; já no caso dos resíduos eletroeletrônicos, a geração é de, em média, 40 milhões de toneladas por ano, segundo relatório da PNUMA (UNITED NATIONS ENVIRONMENT PROGRAMME - UNEP, 2009). O mesmo relatório aponta o Brasil como o país emergente que produz maior volume de lixo eletrônico por pessoa a cada ano, sendo um dos líderes em descarte de celulares, aparelhos de televisão e impressoras. Com relação a geração de resíduos provenientes de celulares, o Brasil assume a segunda colocação, com 2,2 mil toneladas por ano, estando atrás somente da China (UNEP, 2009).

Nesse cenário de elevados índices de consumo e reduzidos tempos de vida útil dos bens, um produto em especial chama atenção: o aparelho celular. Nas últimas duas décadas, esse item deixou de ser um bem restrito a poucos para se tornar parte essencial do cotidiano das pessoas. Diversos modelos e novas tecnologias surgem a todo o momento, fazendo com que o termo obsolescência seja amplamente aplicado. É também nesse contexto que os descartes indevidos geram graves problemas ao meio ambiente.

A logística reversa então surge como uma ferramenta alternativa à questão do grande volume de resíduos eletroeletrônicos gerados. Esta subárea da logística empresarial torna-se importante na medida em que o processo de gerenciamento de resíduos é extremamente complexo e depende de mão de obra especializada $(\mathrm{HOCH}, 2016)$. A mesma autora discorre que a logística reversa também "torna possível tanto o desagravo aos impactos ambientais causados por produtos eletroeletrônicos, quanto o ganho de eficiência e sustentabilidade das operações nas organizações" (HOCH, 2016, p. 9).

Alinhada à necessidade da logística reversa é sancionada em 2010, no Brasil, a Política Nacional de Resíduos Sólidos (PNRS), a qual estabelece um marco regulatório para a sociedade brasileira ao definir um regime de responsabilidade compartilhada sobre o ciclo de vida de diversos produtos e a obrigatoriedade da logística reversa dos resíduos eletroeletrônicos (DEMAJOROVIC e MIGLIANO, 2013; BRASIL, 2010a).

O presente trabalho tem como objetivo avaliar as redes de logística reversa implementadas pelas operadoras de telefonia móvel no Brasil, sob a ótica dos consumidores e também com base na análise dos websites destas. Tal análise segue, propositalmente, uma abordagem sob a ótica do consumidor, a fim de verificar de forma realista a difusão de informações acerca dos canais reversos. 


\section{REVISÃO DA LITERATURA}

\section{O consumo de celulares no Brasil e no mundo}

Nas últimas duas décadas, um pequeno aparelho foi capaz de mudar o cotidiano de milhões de pessoas, permitindo a rápida comunicação e aumentando os fluxos de informações, seja em âmbito regional ou até mesmo global. Esse aparelho, que hoje não pesa mais que 100 gramas (UNEP, 2009) e possuí diversas novas funcionalidades (calculadora, acesso à internet, câmera fotográfica, etc.) é popularmente conhecido como celular. A democratização de seu uso tem se tornado cada vez mais intensa, batendo recordes de consumo com o passar dos anos. A revolução tecnológica observada nas últimas décadas resultou na produção de equipamentos eletroeletrônicos com muitas utilidades, levando, consequentemente, ao aumento na quantidade e diversidade de aparelhos celulares, que rapidamente caem em desuso (TRIGO, ANTUNES e BALTER, 2013). Os mesmos autores também argumentam que o avanço tecnológico e as facilidades oferecidas pelo uso das tecnologias de comunicação vêm mudando profundamente o comportamento humano, sobretudo com relação ao celular, que ao longo dos anos, deixou de ser um produto restrito as classes mais altas para tornar-se popular. O surgimento constante de novas tecnologias e aplicativos são também um dos fatores responsáveis pela manutenção dessa demanda crescente.

Segundo dados da Teleco, em 2013, a produção de celulares apresentou um crescimento de $73,1 \%$ no mês de dezembro, se comparado ao mesmo período do ano anterior. Dados da Anatel indicam que o Brasil terminou março de $2016 \mathrm{com}$ 257,8 milhões de celulares e densidade de 125,42 celulares/100 habitantes (TELECO, 2016). Tais informações corroboram os números levantados pela Pesquisa Nacional por Amostra de Domicílios (Pnad) de 2013, realizada pelo Instituto Brasileiro de Geografia e Estatística (IBGE), que demonstram um avanço de 131,4\% (73,9 milhões de pessoas) no número de portadores de celular, entre os anos 2005 e 2013. A pesquisa também indica que o Distrito Federal foi a unidade da Federação com maior percentual de pessoas com celular no ano de 2013, com 89,4\% (IBGE, 2013).

Uma análise macro revela que o Brasil, no ano de 2014, foi o 5o principal mercado de celulares no mundo, com cerca de 281 milhões de aparelhos (TELECO, 2016). China, Índia, Estados Unidos e Indonésia são os quatro países à frente do Brasil, em termos de quantidade absoluta e taxa de aumento anual de celulares. A União Internacional de Telecomunicações (UIT), agência da Organização das Nações Unidas (ONU) especializada em tecnologias de informação e comunicação, em seu levantamento realizado no ano de 2016, mostrou que a cobertura celular está bastante disseminada, com $95 \%$ da população mundial (ou 7 bilhões de pessoas) vivendo em áreas cobertas ao menos pela tecnologia 2G (ONU/BR, 2016). Dessa forma, é possível observar que os índices de consumo de aparelhos celulares são crescentes e atingiram níveis elevados em diversas nações. Essa massificação é um dos pilares para a análise feita por esse trabalho, representando o primeiro ponto da linha lógica do consumo de celulares. A Figura 1 apresenta a evolução do consumo de celulares no mundo. 


\section{Celulares no Mundo}

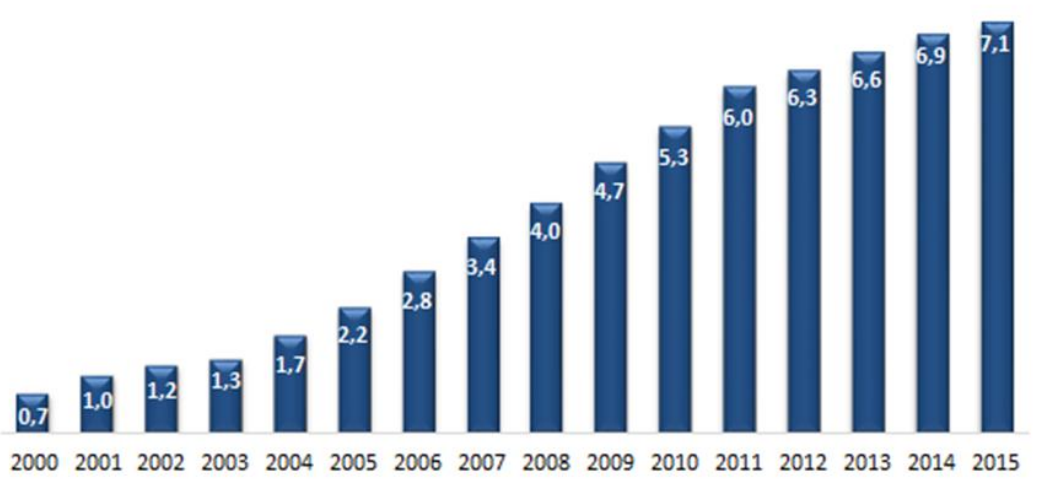

Fonte: ONU/UIT, Wireless Intelligence e GSA/Informa apud Teleco (2016)

A Figura 1 demonstra o aumento do consumo de celulares no mundo ao longo dos últimos 15 anos. Observa-se, portanto, um crescimento vertiginoso nesse segmento, o que demanda uma análise mais apurada dos fatores relacionados ao uso de aparelhos celulares. $O$ volume de celulares no mundo hoje, segundo as Nações Unidas, é de 3 bilhões de aparelhos e, desse total, somente $15 \%$ é reciclado, a outra parte é enviada a países pobres (China, Nigéria, Gana) como produtos de segunda linha (MAGERA, 2013). A seção seguinte levanta os principais pontos a respeito do ciclo de vida desse produto, fornecendo importantes informações e características dos aparelhos celulares para esse estudo.

\section{Logística reversa e Política Nacional de resíduos sólidos}

Enquanto que a logística direta pode ser entendida como um processo divergente, onde o produto sai de um fabricante e chega a diversos clientes, a logística reversa pode ser abordada como um processo convergente, onde os produtos saem de diversos clientes chegando a uma ou poucas empresas receptoras (MIGUEZ, 2010).

De acordo com De Brito (2003), embora a logística reversa tenha tomado maior importância nos últimos anos, ela não é um tema novo. Não se pode precisar com exatidão quando surgiu sua nomenclatura, mas desde os anos 70, termos como "canais reversos" ou "fluxo reverso" já existiam na literatura internacional (GUILTINAN apud MIGUEZ, 2010). Na década de 1990 surge, então, a definição formal de logística reversa, dada pelo Council of Supply Chain Management Professionals (MIGUEZ,2010).

Entretanto, os estudos sobre os canais de distribuição reversos são relativamente recentes no Brasil (LEITE, 2003). O enfoque majoritário sobre a logística direta transpassou-se gradativamente à logística reversa na medida em que as questões ambientais passaram a incorrer sobre as empresas em virtude do aumento das legislações ambientais restritivas, tornando-a uma ferramenta 
importante nas estratégias empresariais (RAZZOLINI FILHO e BERTÉ, 2009; LEITE, 2003; CHAVES e BATALHA, 2006). Dessa forma, Daher, Silva e Fonseca (2006) discorrem que a logística reversa vem se destacando no meio empresarial por ter se tornado uma importante ferramenta ao planejamento jurídico-ambiental das organizações.

Hoje, diversas definições e conceitos são apresentados na literatura. Dowlatshahi (2000) define logística reversa como o processo no qual um fabricante aceita, sistematicamente, o retorno dos produtos previamente encaminhados, ou parte deles, para reciclar, remanufaturar ou descartar. Sob a ótica do meio-ambiente, Kroon e Vrijens (1995) afirmam que a logística reversa é caracterizada pelas habilidades de gerenciamento logístico e atividades relacionadas com a redução, gerenciamento e descarte de resíduos.

Uma definição relativa à visão geral do processo caracteriza a logística reversa como uma área da logística empresarial que planeja, opera e controla o fluxo e as informações logísticas correspondentes, do retorno dos bens de pósvenda e de pós-consumo ao ciclo de negócios ou ao ciclo produtivo, através dos canais de distribuição reversos, agregando-lhes valor de diversas naturezas: econômico, ecológico, legal, logístico, de imagem corporativa, entre outros (LEITE, 2003).

Fleischmann et al. (2000) argumentam que a Logística Reversa inclui desde as atividades logísticas de produtos usados que não tem mais serventia aos usuários, bem como a recolocação de produtos ainda utilizáveis no mercado. Para o mesmo autor, a Logística Reversa de Resíduos Eletroeletrônicos (REEE) envolve também um processo de recuperação material, uma vez que muitos desses resíduos contêm metais valiosos.

Ademais é importante enfatizar que a logística reversa possui duas subáreas: pós-venda e pós-consumi. A diferença entre os dois principais tipos de logística reversa, elucidados por Leite (2003) e Guarnieri et al. (2006), reside no processo de retorno dos bens: enquanto que na logística reversa de pós-venda tais produtos podem retornar aos diferentes elos da cadeia de distribuição direta, na logística reversa de pós-consumo os bens retornam ao ciclo produtivo por meio de diversos canais de distribuição reversos específicos (MOREIRA e GUARNIERI, 2016; LEITE, 2003; RAZZOLINI FILHO e BERTÉ, 2009). Tais canais, utilizados durante o processo reverso do pós-consumo, podem ser o retorno ao fornecedor, o direcionamento a mercados secundários ou o descarte, através dos meios de revenda, reciclagem, recondicionamento e desmanche (LACERDA, 2002; LEITE, 2003).

No campo legislativo, a PNRS - Lei 12.305/2010 representou um importante avanço no que se refere à logística reversa e gestão de resíduos sólidos. Até então, não existia no Brasil uma regulamentação específica para tratar da questão do descarte de produtos como os celulares. Segundo Miguez (2010), a legislação brasileira tratava a questão do descarte de substância sólidas de uma maneira generalizada.

Uma das maiores inovações da Lei 12.305/10 é tratada em seu artigo 30, o qual estabelece a responsabilidade compartilhada pelo ciclo de vida dos produtos, a ser implementada de forma individualizada e encadeada, abrangendo os fabricantes, importadores, distribuidores e comerciantes, os consumidores e os titulares dos serviços públicos de limpeza urbana e de manejo 
de resíduos sólidos, consoante as atribuições e procedimentos previstos (GUARNIERI, 2013; FONTES, 2013).

Segundo Demajorovic et al. (2012) um dos principais setores envolvidos com a questão da Logística Reversa é o da telefonia móvel, onde a PNRS passou a obrigar os fabricantes de eletroeletrônicos, incluindo celulares, a implementarem programas de LR de aparelhos e baterias. Nesse contexto é apropriado destacar que os acordos setoriais, um dos instrumentos da lei, são de extrema importância, na medida em que buscam a implementação da responsabilidade compartilhada pelo ciclo de vida dos produtos por meio de atos de natureza contratual entre o Poder Público e os fabricantes, importadores, distribuidores ou comerciantes (MINISTÉRIO DO MEIO AMBIENTE - MMA, 2017).

Guarnieri, Silva e Levino (2016) realizaram um estudo sobre a estrutura de logística reversa necessária para os resíduos eletroeletrônicos, decorrente da obrigatoriedade estabelecida pela PNRS. Os autores estruturaram o problema através do método SODA (Strategic Options Development and Analysis) levando em consideração a opinião de stakeholders envolvidos nos acordos setoriais também estabelecidos pela PNRS e encontraram as seguintes categorias de ação: Estratégica, Econômica, Ambiental e Social.

Cabe ressaltar que com o intuito de atender à PNRS e baseado no Acordo Setorial de eletroeletrônicos, que está na iminência de sua consolidação, onze fabricantes de produtos eletroeletrônicos se uniram e criaram a Green Eletron, uma empresa especializada na logística reversa desses equipamentos (GUARNIERI, 2016; ABINEE, 2016). A Green Eletron assume a postura de entidade gestora da logística reversa nesse setor e, a partir de 2018, terá que coletar, anualmente, $17 \%$ do peso de todos os produtos comercializados do ano anterior (GUARNIERI, 2016).

\section{MÉTODOS E TÉCNICAS DE PESQUISA}

Seguindo a classificação discorrida por Silva e Menezes (2005, p. 20), o presente trabalho enquadra-se, do ponto de vista de sua natureza, como sendo uma pesquisa aplicada, cujo objetivo é "gerar conhecimentos para aplicação prática e dirigidos à solução de problemas específicos". Com relação aos seus objetivos, a pesquisa é classificada como descritiva. Andrade (2010) e Gil (2007) afirmam que a pesquisa descritiva tem como foco central a observação, o registro, a análise, a classificação e a interpretação de fatos sem que haja intervenção ou manipulação dos dados pelo pesquisador. Sob a ótica da forma de abordagem do problema, a classificação é mista (quali-quantitativa), na qual os dados quantitativos e qualitativos se complementam, uma vez que a realidade abrangida por eles interage dinamicamente, excluindo qualquer dicotomia (CHIZZOTTI, 2006; MINAYO, 1994; SILVA e MENEZES, 2005).Quanto aos procedimentos técnicos utilizados nesse trabalho, foram o levantamento (survey) e a pesquisa documental.

A amostra selecionada para essa pesquisa seguiu critérios não probabilísticos, e pode ser classificada na categoria de amostras acidentais, que tem como principal característica sua composição ao acaso (SILVA e MENEZES, 2005). A população considerada baseou-se nos números de acesso em operação 
no ano de 2017 que totalizaram, segundo a Anatel, 242 milhões, aproximadamente. A metodologia utilizada para a definição da amostra teve por base os seguintes dados: população de 242.335.205, que representa a quantidade total de acessos em operação em 2017; erro amostral de 5\%; nível de confiança de $95 \%$; e proporção de $50 \%$, considerando a amostra heterogênea. Com o uso desses dados e de uma calculadora de tamanho de amostras, disponibilizada online por Albuquerque (2012), constatou-se que o número mínimo de respondentes deveria ser 385.

Fazem parte da amostra todo e qualquer indivíduo que possui pelo menos 1 (um) aparelho celular, considerando-se os celulares comuns e os smartphones, e que já efetuaram ao menos 1 (uma) troca desse bem. Não houveram restrições de sexo, idade, localização, escolaridade ou renda familiar. 0 resultado da coleta dos dados superou a meta preestabelecida, alcançando a marca de 596 respostas, o que ultrapassou em $56 \%$ a amostra calculada de 385 respondentes.

O instrumento de pesquisa para o survey foi o questionário com perguntas fechadas, de múltipla escolha e também com escalas do tipo Likert. As escalas aplicadas possuíam cinco possíveis respostas, a saber: 1 - discordo totalmente; 2 - discordo parcialmente; 3 - não concordo nem discordo; 4 - concordo parcialmente; e 5 - concordo totalmente.A formulação do instrumento de pesquisa utilizou como plataforma o formulário do Google Forms. A escolha por esse meio deve-se a facilidade em sua utilização, tanto para o editor quanto para os respondentes, a capacidade de se atingir um maior número de pessoas a custo zero e a facilidade na análise dos dados.

O questionário foi embasado principalmente nos instrumentos de Domingues, Guarnieri e Streit (2016) e Demajorovic et al. (2012) e busca verificar como os consumidores avaliam as redes de logística reversa implementadas pelas suas respectivas operadoras de telefonia celular. A avaliação dos websites utilizou o codificador de Demajorovic et al. (2012). A análise dos dados ocorreu por meio da estatística descritiva, com base em cálculos de frequência, média, moda, mediana e desvio padrão. A análise documental utilizou a análise de conteúdo categorial temática de Bardin (1977).

\section{Caracterização do setor de telefonia móvel no Brasil}

Essa seção tem por objetivo caracterizar o setor de serviço móvel pessoal (telefonia móvel) no Brasil, visando fornecer dados para atingir-se os dois últimos objetivos específicos desse trabalho. Para tal, colheram-se informações de relatórios consolidados obtidos da Agência Nacional de Telecomunicações (ANATEL), da Teleco e das próprias operadoras de telefonia celular, sendo, portanto, dados de natureza primária e secundária. Essa seção objetiva, também, caracterizar o mercado consumidor que constitui a amostra da pesquisa, composta por pessoas que possuem aparelho celular e já efetuaram ao menos 1 (uma) troca.

O Brasil registrou ao final do primeiro quadrimestre de 2016 256,43 milhões de linhas ativas na telefonia móvel, com teledensidade de 124,66 acessos por 100 habitantes (ANATEL, 2016). A Tabelas 1 e as Figuras 6 e 7 demonstram a densidade da telefonia móvel nas 27 (vinte e sete) Unidades da Federação, nas 
cinco regiões do Brasil e a evolução de acessos de telefonia móvel de 2004 a 2016 no Brasil, respectivamente:

Tabela 1 - Densidade SMP por 100 habitantes (por UF)

\begin{tabular}{|c|c|c|}
\hline Regiões & $\begin{array}{l}\text { Acessos em } \\
\text { Operação } \\
\end{array}$ & $\begin{array}{c}\text { Densidade por } 100 \\
\text { Hab. }\end{array}$ \\
\hline Centro-Oeste & 21.727 .403 & 139,26 \\
\hline DF & 5.595 .641 & 189,20 \\
\hline GO & 8.592 .615 & 128,73 \\
\hline MS & 3.369 .207 & 125,95 \\
\hline MT & 4.169 .940 & 126,56 \\
\hline Nordeste & 63.837 .442 & 112,34 \\
\hline $\mathrm{AL}$ & 3.680 .785 & 109,73 \\
\hline BA & 16.755 .934 & 109,82 \\
\hline CE & 10.690 .688 & 119,40 \\
\hline MA & 6.067 .122 & 87,47 \\
\hline PB & 4.618 .516 & 115,74 \\
\hline PE & 11.688 .564 & 124,44 \\
\hline $\mathrm{Pl}$ & 3.879 .308 & 120,82 \\
\hline RN & 4.160 .800 & 120,00 \\
\hline SE & 2.295 .725 & 101,56 \\
\hline Norte & 17.861 .902 & 101,23 \\
\hline$A C$ & 806.233 & 99,15 \\
\hline AM & 3.611 .673 & 90,63 \\
\hline AP & 791.801 & 101,66 \\
\hline PA & 8.119 .954 & 98,50 \\
\hline RO & 2.160 .482 & 121,19 \\
\hline $\mathrm{RR}$ & 488.350 & 95,18 \\
\hline TO & 1.883 .409 & 123,22 \\
\hline Sudeste & 115.391 .357 & 133,82 \\
\hline ES & 3.942 .538 & 99,52 \\
\hline MG & 24.460 .384 & 116,67 \\
\hline RJ & 22.939 .849 & 138,01 \\
\hline SP & 64.048 .586 & 143,35 \\
\hline Sul & 37.610 .991 & 127,94 \\
\hline PR & 14.271 .517 & 127,11 \\
\hline RS & 14.825 .595 & 131,39 \\
\hline SC & 8.513 .879 & 123,64 \\
\hline
\end{tabular}

Fonte: ANATEL (2016)

Os dados apresentados pela Tabela 1 mostram que o Distrito Federal (DF) é a unidade da Federação que possui o maior índice de teledensidade, com 189,20 acessos a cada 100 habitantes. Porém, esse valor não reflete a quantidade absoluta de acessos em operação, fazendo com que o DF ocupe a 13a posição nesse quesito, atrás dos líderes São Paulo, Minas Gerais e Rio de Janeiro (o 10 com mais de 60 milhões de acessos e o 2 e 3 com mais de 20 milhões). 
De acordo com os números apresentados pela Tabela 1, o Distrito Federal é a Unidade Federativa mais próxima de completar 2 linhas telefônicas por habitante e fazendo parte do grupo de estados com os maiores índices de teledensidade, composto também por São Paulo, Rio de Janeiro, Rio Grande do Sul, Goiás e Paraná.

Tabela 2 - Acessos em operação por Grupo Econômico

\begin{tabular}{cccc}
\hline $\begin{array}{r}\text { Posição } \\
\text { no mercado }\end{array}$ & $\begin{array}{c}\text { Grupo } \\
\text { econômico }\end{array}$ & $\begin{array}{c}\text { Acessos em } \\
\text { operação }\end{array}$ & $\begin{array}{c}\text { participação } \\
\text { (em relação } \\
\text { ao mercado) }\end{array}$ \\
\hline $1^{\circ}$ & Vivo & 74.074 .202 & $30,57 \%$ \\
$2^{\circ}$ & Tim & 61.348 .533 & $25,32 \%$ \\
$3^{\circ}$ & Claro & 60.207 .677 & $24,84 \%$ \\
$4^{\circ}$ & Oi & 42.081 .963 & $17,37 \%$ \\
\hline
\end{tabular}

Fonte: ANATEL (2017)

Os dados apresentados pela Tabela 2 possibilitam a análise do mercado de operadoras telefônicas em termos de competitividade, apresentando o Market Shareda telefonia móvel no País. Embora o Open Market (vendas nos canais que não a operadora) represente $52 \%$ da comercialização dos dispositivos móveis, as operadoras seguem sendo o principal canal de vendas para esse tipo de aparelho (IDC, 2013).

\section{Caracterização da amostra}

A amostra da pesquisa é composta por 344 respondentes do sexo feminino, que corresponde a $57,72 \%$ e 252 do sexo masculino, que corresponde a $42,28 \%$.

Figura 2 - Faixa etária dos respondentes

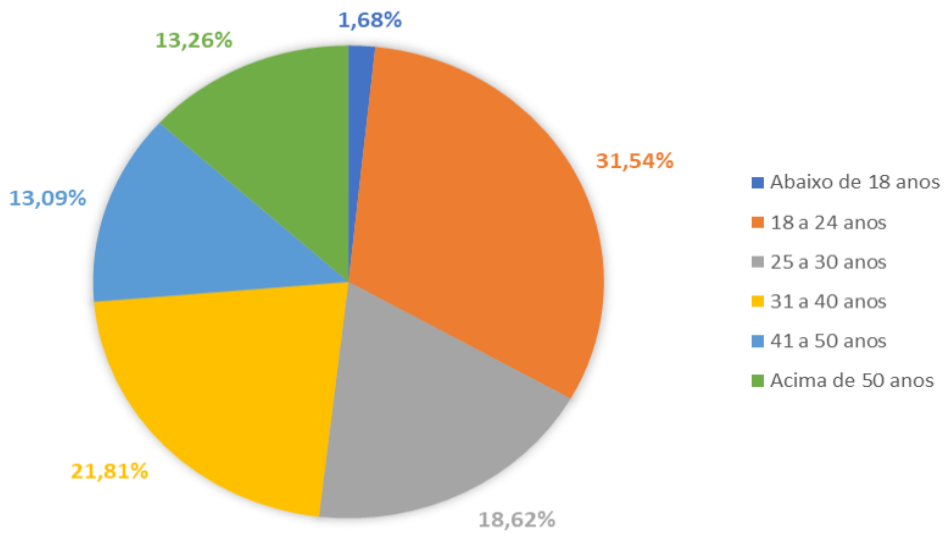

Fonte: Autoria própria (2017)

A maioria dos indivíduos pertence à faixa etária de 18 a 24 anos, seguido pelos respondentes com idade entre 31 a 41 anos e, em terceiro lugar, os com idade entre 25 a 30 anos (Figura 2). A menor categoria etária é representada pelos indivíduos que não alcançaram a maioridade, com apenas 10 respondentes. 
Figura 3 - Estado (UF) dos respondentes

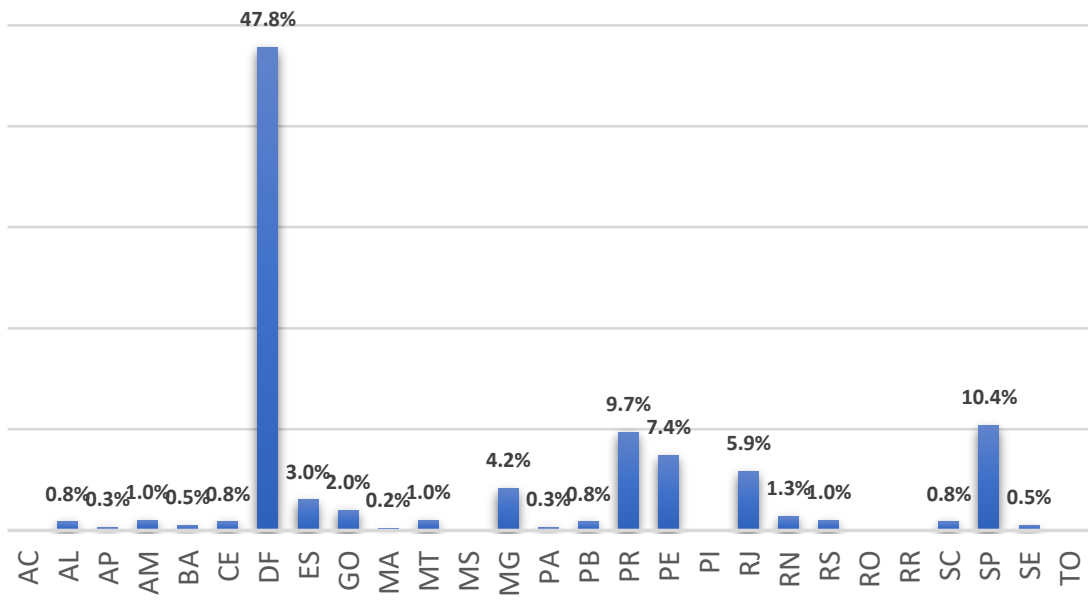

Fonte: Autoria própria (2017)

Com relação aos estados (UF) que os indivíduos residem, a Figura 3 demonstra que grande parcela dos respondentes $(47,8 \%)$ é do Distrito Federal. Tal número pode ser explicado devido à facilidade de divulgação e coleta de dados junto a esses indivíduos, tendo em vista a proximidade geográfica e a utilização de canais com alta capilaridade, sobretudo os relacionados ao corpo discente da Universidade de Brasília. As cinco seguintes Unidades Federativas (UF) com maiores representatividades na amostra, em ordem, são: São Paulo $(10,4 \%)$, Paraná $(9,7 \%)$, Pernambuco $(7,4 \%)$, Rio de Janeiro (5,9\%) e Minas Gerais $(4,2 \%)$.

Figura 4 - Nível de instrução

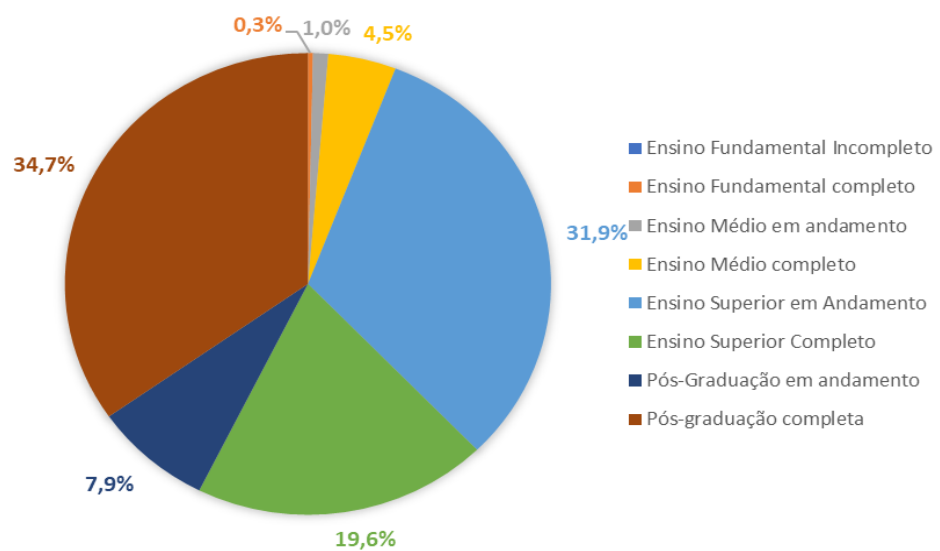

Fonte: Autoria própria (2017)

A Figura 4 aponta que $86,2 \%$ dos respondentes cursam ou possuem Ensino Superior, sendo que $31,9 \%$ ainda estão em vias de se formar, $19,6 \%$ já completaram o 3o grau e 34,7\%, a maior fatia da amostra, possui pós-graduação 
completa. Dessa forma, é possível inferir que uma parcela expressiva da amostra possui elevado nível de instrução.

Figura 5 - Renda Familiar dos respondentes

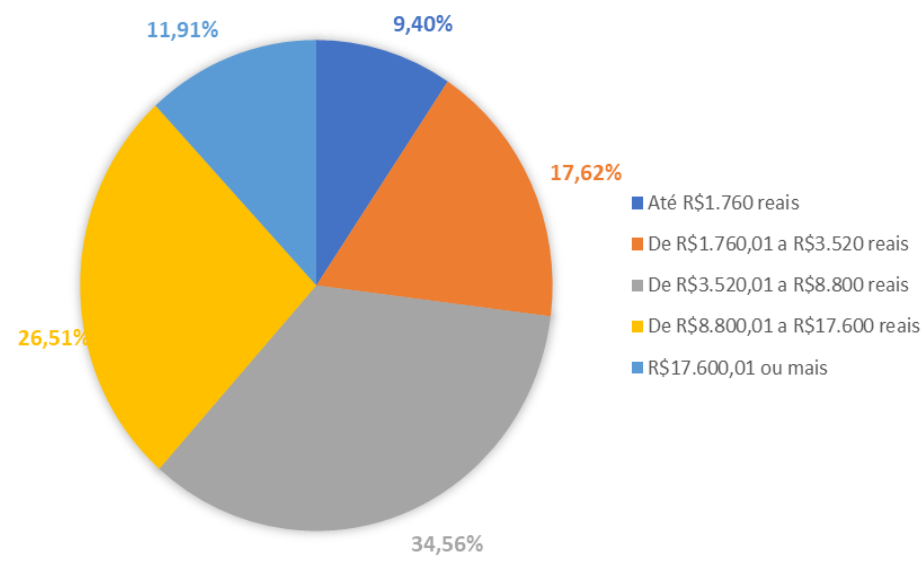

Fonte: Autoria própria (2017)

Por fim, no que diz respeito à Renda Familiar, a Figura 5 mostra que a maioria dos respondentes $(34,56 \%)$ recebe de 4 a 10 salários mínimos, seguido por $26,51 \%$ dos indivíduos que recebem de 10 a 20 salários mínimos. Apenas $11,91 \%$ da amostra tem renda superior a 20 salários mínimos ( $R \$ 17.600,00)$ e, a menor categoria no que diz respeito à Renda Familiar (até 2 salários mínimos) é composta por 56 respondentes, ou $9,4 \%$ da amostra. O elevado poder aquisitivo da amostra pode ser justificado pelo fato de $47,8 \%$ dos respondentes residirem no Distrito Federal, unidade federativa com a maior renda per capita do país (IBGE, 2017). 


\section{Avaliação sob a ótica do consumidor}

A avaliação da logística reversa das operadoras de telefonia móvel no Brasil sob a ótica dos consumidores é apresentada a seguir. A Figura 6 apresenta a distribuição dos respondentes considerando as operadoras brasileiras.

Figura 6-Operadoras de telefonia celular

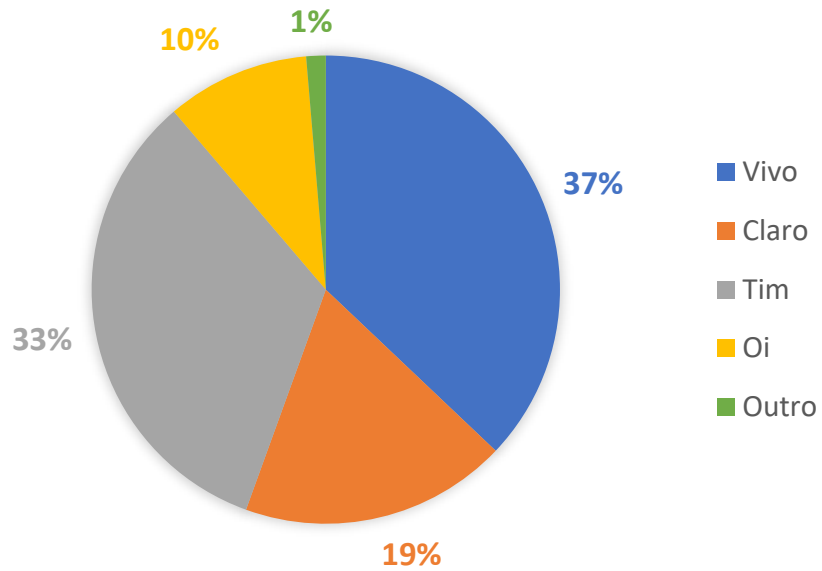

Fonte: Autoria própria (2017)

De acordo com a Figura 6 verifica-se que a principal operadora de telefonia móvel entre os indivíduos pesquisados foi a Vivo, com $37 \%$, seguido pela Tim, com 33\%. Em um nível mais abaixo em termos de usuários encontra-se a Claro, com 19\%, 14 pontos percentuais atrás do segundo colocado (Tim). Em última posição está a $\mathrm{Oi}$, com $10 \%$ do total. Os dados obtidos por essa pesquisa corroboram com as informações fornecidas pela Anatel (2017), que também posiciona, nessa ordem, as operadoras Vivo, Tim, Claro e Oi como as principais no mercado. Embora as porcentagens de participação não estejam em consonância, sobretudo no que se refere à diferença entre a Claro e a Tim, pode-se inferir que essa pesquisa valida a relatividade das empresas em termos de Market Share.

A PNRS, ao instituir o conceito de Responsabilidade Compartilhada, exige também que as operadoras de telefonia móvel no Brasil comuniquem e implementem sistemas de logística reversa, sobretudo porque essas também se enquadram como comerciantes de aparelhos celulares, conforme demonstrado pela IDC (2013). A Figura 7 evidencia as principais questões relacionadas a esse tema. 
Figura 7 - Pesquisa de informações e classificação dos websites das operadoras de celular

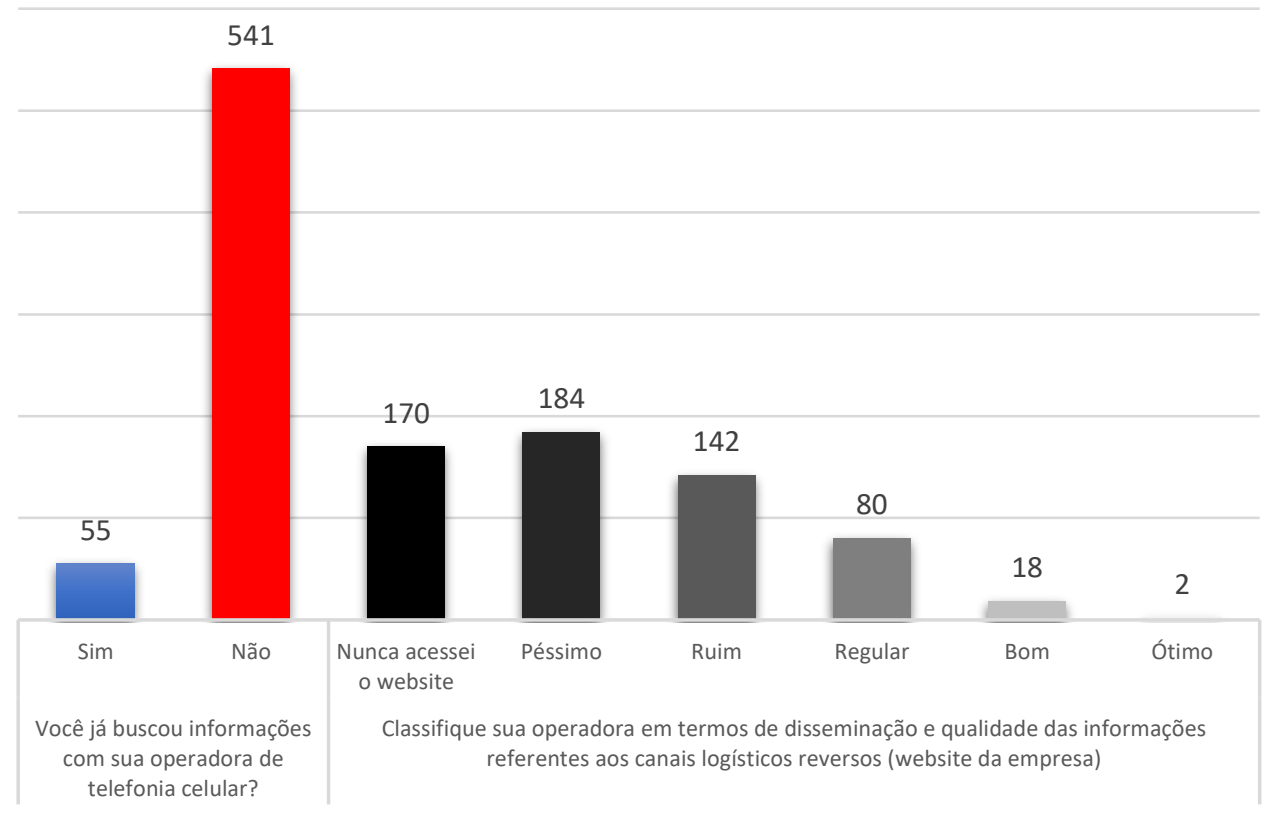

Fonte: Autoria própria (2017)

Duas perguntas foram feitas aos respondentes da pesquisa, como se pode observar na Figura 7. A primeira questiona se o indivíduo já buscou qualquer tipo de informação relacionada aos meios disponíveis de descarte junto a sua operadora. Menos de $10 \%$ da amostra já procedeu com o levantamento dessas informações e, a grande maioria, representada por 541 respondentes, nunca buscou tais dados. A segunda indagação visa avaliar os websites dessas operadoras em uma escala de 1 a 5, traduzida pelos adjetivos de qualidade péssimo, ruim, regular, bom e ótimo. Uma sexta opção permitia ao indivíduo informar que nunca acessou o website da operadora para buscar esse tipo de informação. Aproximadamente $29 \%$ dos respondentes declararam nunca terem acessado os websites dessas empresas. Mais da metade da amostra, precisamente $54,7 \%$, avaliou negativamente (péssimo ou ruim) a disseminação e qualidade das informações prestadas nos sites das operadoras referentes aos seus canais logísticos reversos. Outra parcela, correspondente a $13 \%$ do total, classificou os websites como regulares. E a menor fatia da amostra, apenas $3 \%$, avaliou de forma positiva (bom ou ótimo) esse canal de informações.

Pode-se observar uma discrepância entre os resultados do primeiro questionamento, que demonstra que mais de $90 \%$ dos indivíduos nunca buscaram informações sobre o descarte de celulares, e os resultados da segunda questão, que apontou somente 170 respondentes que declararam nunca terem acessado os websites das operadoras. Ou seja, 371 indivíduos (ou 62\% da amostra), avaliaram a qualidade das informações prestadas pelas operadoras em seus websites mesmo nunca tendo, objetivamente, buscado tais informações. É possível inferir que o motivo dessa avaliação se deva a baixa divulgação visual no âmbito desses websites, que acabam destacando mais seus planos e promoções, conforme observado por esse estudo durante seus mapeamentos. Os resultados dessa avaliação são demonstrados na subseção 4.2. A análise mais coerente explica que muitos indivíduos acessam os websites das operadoras com outros objetivos que não a busca de informações acerca dos descartes de celulares. 
Mesmo que o propósito central não seja o levantamento dessas informações, a navegação nesses canais permite aos respondentes avaliarem a disseminação e qualidade dos programas logísticos reversos em termos de exposição e destaque de tais elementos, ou seja, o quanto as operadoras estão divulgando esses dados.

Por fim, quatro afirmativas de escala Likert coletaram dados relacionados a Logística Reversa das operadoras de telefonia móvel no Brasil. A escala do questionário possuía cinco possíveis níveis, a saber: 1 - discordo totalmente; 2 discordo parcialmente; 3 - não concordo nem discordo; 4 - concordo parcialmente; e 5 - concordo totalmente. Todos esses itens estavam pautados sob ótica do consumidor e tinham por objetivo medir o nível de conhecimento acerca dos programas de logística reversa praticados pelas operadoras e as percepções dos consumidores sobre a obrigatoriedade legal imposta a essas, além da eficiência da divulgação de informações referentes aos canais reversos implementados por essas entidades. A Tabela 3 demonstra as principais análises obtidas.

Tabela 3 - Médias, modas e medianas das perguntas referentes à Logística Reversa

\begin{tabular}{cccc}
\hline Afirmativa & Média & Moda & Mediana \\
\hline $\begin{array}{c}\text { Conheço programas de logística reversa da } \\
\text { minha operadora de celular. }\end{array}$ & 1,44 & 1 & 1 \\
$\begin{array}{c}\text { Acredito que a minha operadora de celular } \\
\text { deveria ser obrigada por lei a prestar maiores } \\
\text { informações sobre programas de logística } \\
\text { reversa. }\end{array}$ & 4,34 & 5 & 5 \\
$\begin{array}{c}\text { Acredito que a minha operadora de celular } \\
\text { deveria investir mais na divulgação de } \\
\text { informações sobre programas de logística } \\
\quad \text { reversa. }\end{array}$ & 4,52 & 5 & 5 \\
$\begin{array}{c}\text { Acredito que a minha operadora de celular faz } \\
\text { um bom trabalho na divulgação de informações } \\
\text { sobre programas de logística reversa. }\end{array}$ & 1,61 & 1 & 1 \\
\hline
\end{tabular}

Fonte: Autoria própria (2017)

As afirmativas 1 e 4 que tratam sobre a logística reversa apresentam médias, modas e medianas baixas, permitindo as seguintes avaliações: primeiramente, boa parcela dos respondentes não conhece os programas de logística reversa de suas operadoras; em seguida, esses indivíduos discordam, de forma geral, que suas operadoras fazem um bom trabalho na divulgação de informações sobre os programas de LR.

Já as afirmativas 3 e 5 apresentam médias, modas e medianas elevadas, permitindo analisar que boa parte dos respondentes concordam que suas operadoras deveriam ser obrigadas por lei a prestar maiores informações sobre seus programas de logística reversa e também deveriam investir mais na divulgação dos mesmos. A Tabela 4 elenca os desvios-padrão e variâncias extraídos da seção do questionário que aborda a logística reversa das operadoras de celulares. 
Tabela 4 - Desvios-padrão e variâncias referentes a Logística Reversa

\begin{tabular}{ccc}
\hline Pergunta & $\begin{array}{c}\text { Desvio } \\
\text { Padrão }\end{array}$ & Variância \\
\hline $\begin{array}{c}\text { Conheço programas de logística reversa da minha } \\
\text { operadora de celular. }\end{array}$ & 0,96 & 0,93 \\
$\begin{array}{c}\text { Acredito que a minha operadora de celular deveria ser } \\
\text { obrigada por lei a prestar maiores informações sobre } \\
\text { programas de logística reversa. }\end{array}$ & 1,05 & 1,10 \\
$\begin{array}{c}\text { Acredito que a minha operadora de celular deveria investir } \\
\text { mais na divulgação de informações sobre programas de } \\
\quad \text { logística reversa. }\end{array}$ & 0,91 & 0,83 \\
$\begin{array}{c}\text { Acredito que a minha operadora de celular faz um bom } \\
\text { trabalho na divulgação de informações sobre programas de } \\
\text { logística reversa. }\end{array}$ & 1,01 & 1,02 \\
\hline
\end{tabular}

Fonte: Autoria própria (2017)

Todos os itens da escala descritos pela Tabela 4 possuem, relativamente, baixos índices de desvio padrão e variância. Ou seja, de forma geral, os respondentes estão em consonância entre si e possuem opiniões parecidas ao discordarem ou concordarem com as quatro afirmativas dessa seção.

Destaca-se um elevado nível de consenso nos itens que tratam sobre o conhecimento dos programas logísticos reversos das operadoras e acerca dos investimentos em divulgação de informações desses programas. Na primeira, $88 \%$ da amostra informaram não terem conhecimento referente às ações de LR implementadas por suas operadoras de celular. Na segunda, $87 \%$ dos respondentes concordam que suas operadoras deveriam investir mais na disseminação de informações sobre seus programas de logística reversa.

\section{Avaliação dos sites das operadoras}

A presente seção tem por objetivo mapear as iniciativas das quatro principais operadoras de telefonia móvel do Brasil no que diz respeito à logística reversa. As informações foram coletadas dos websites oficiais das operadoras Vivo, Tim, Claro e $\mathrm{Oi}$, não sendo analisados sites desvinculados aos domínios principais dessas empresas.

A análise a seguir fez o uso de um codificador adaptado, utilizado por Demajorovic et al. (2012) para analisar as informações sobre LR encontradas nos websites de cinco fabricantes de aparelhos celulares. A Tabela 5 demonstra as principais informações extraídas nessa análise.

Tabela 5 - Informações sobre LR encontradas na análise dos websites

\begin{tabular}{lllll}
\hline \multicolumn{1}{c}{ Informações sobre... } & Vivo & Tim & Claro & Oi \\
\hline LR na página inicial & & & \\
Descarte de celulares na página inicial & & & \\
$\begin{array}{l}\text { Descarte de celulares na ferramenta de busca do } \\
\text { site }\end{array}$ & SIM & \\
\hline
\end{tabular}


Reciclagem de celulares na ferramenta de busca do site

Seus próprios programas de LR

Locais de descarte (celulares)

SIM

Destinação dos produtos coletados

Efeitos prejudiciais do descarte inadequado de celulares

SIM SIM SIM SIM

Benefícios da reciclagem para o meio ambiente

SIM

SIM

Fonte: Autoria própria (2017)

Conforme expresso pela Tabela 5 observa-se que as quatro operadoras não expõem nas páginas iniciais de seus websites informações sobre logística reversa e descarte de celulares. Durante a análise, constatou-se a preferência pelas exposições de pacotes promocionais e serviços fornecidos aos clientes. 0 levantamento efetuado utilizou a ferramenta de pesquisa do navegador Google Chrome, onde as palavras chaves utilizadas foram: descarte, logística reversa e reciclagem. Além disso, um exame minucioso foi efetuado em todas as quatro páginas iniciais, não sendo, portanto, constatada nenhuma informação que atenda aos dois primeiros critérios do codificador.

No que diz respeito à utilização da ferramenta de busca dos websites para o levantamento de informações relacionadas ao descarte e reciclagem de celulares, constatou-se que apenas a operadora Tim apresentou resultados satisfatórios. Nesse ponto, cabe destacar que os websites da Vivo e Claro não exibem em suas páginas principais essa ferramenta, devendo o usuário fazer a referida busca explorando o mapa do site. Por fim, a operadora Oi não apresentou informações suficientes após a utilização da barra de busca. As palavras chaves utilizadas para o levantamento desses dados foram: descarte, logística reversa e reciclagem.

Com relação aos próprios programas de logística reversa e indicação de locais para o descarte de aparelhos celulares, as quatro operadoras apresentam em seus websites tais informações. Entretanto, a busca dessas ocorreu de forma bastante trabalhosa, em virtude da falta de destaque para tais elementos. Os programas, de cada operadora são denominados da seguinte forma: Reciclar Pega Bem (Vivo), Recarregue o Planeta (Tim), Claro Recicla (Claro) e Descarte Certo (Oi). Cabe destacar que a $\mathrm{Oi}$, de acordo com seu último relatório de sustentabilidade, abriu processo licitatório para contratação de fornecedor de logística e de destinação final adequada desses resíduos no ano de 2015, que hoje tem como responsável titular a gestora Descarte Certo.

Todas as operadoras disponibilizam em muitas de suas lojas urnas coletoras de aparelhos celulares. Porém, nenhuma delas especifica para onde os materiais coletados são destinados, apenas informando, de forma genérica, que os itens angariados são encaminhados a diversas indústrias recicladoras no Brasil ou no exterior. Destaca-se que essa pesquisa é realizada apenas nos websites oficiais e domínios conexos das operadoras de telefonia móvel, não sendo, portanto, analisados relatórios gerenciais ou outras fontes que possam especificar tais informações.

Por fim, no que diz respeito às exposições sobre os efeitos prejudiciais do descarte inadequado de celulares e benefícios da reciclagem para o meio 
ambiente, verificou-se que somente a Claro e a Oi abordam esses dois itens em seus websites; já a Tim especifica apenas os benefícios da reciclagem para o meio ambiente; e não foram encontradas informações objetivas sobre esses dois pontos no website da Vivo. Embora seja possível identificar a abordagem de tais elementos em 3 operadoras de telefonia móvel, em todas elas as informações são bastante superficiais, não destrinchando, sobretudo, os impactos e consequências dos descartes indevidos.

De acordo com Demajorovic et al. (2012), a Política Nacional de Resíduos Sólidos obriga as empresas a gerarem informações sobre seus respectivos produtos que orientem os consumidores acerca dos riscos socioambientais, formas seguras de acondicionamento e caminhos para a devolução dos bens pósconsumo. Uma vez as operadoras de telefonia móvel também atuando como comerciantes de aparelhos celulares (IDC, 2013), a responsabilidade compartilhada incide sobre essas, e, caso seja identificado qualquer disposição ou uso inadequado de resíduos sólidos, sanções administrativas, civis e criminais serão aplicadas (BRAGA FILHO et al., 2010). A análise preliminar dos websites das operadoras brasileiras constatou que esse importante meio de comunicação ainda carece de informações, embora cumpram o que está definido pela lei, mesmo que de forma superficial.

Com o mapeamento dos websites das operadoras de telefonia móvel concluído, encerra-se a seção que analisa e discute os principais resultados obtidos por esse trabalho de conclusão de curso. A figura 8 ilustra as frequências de cada categoria de avaliação, seguindo por base as quatro principais operadoras de telefonia móvel no Brasil.

Figura 8 - Operadoras de celular versus avaliação das informações do website

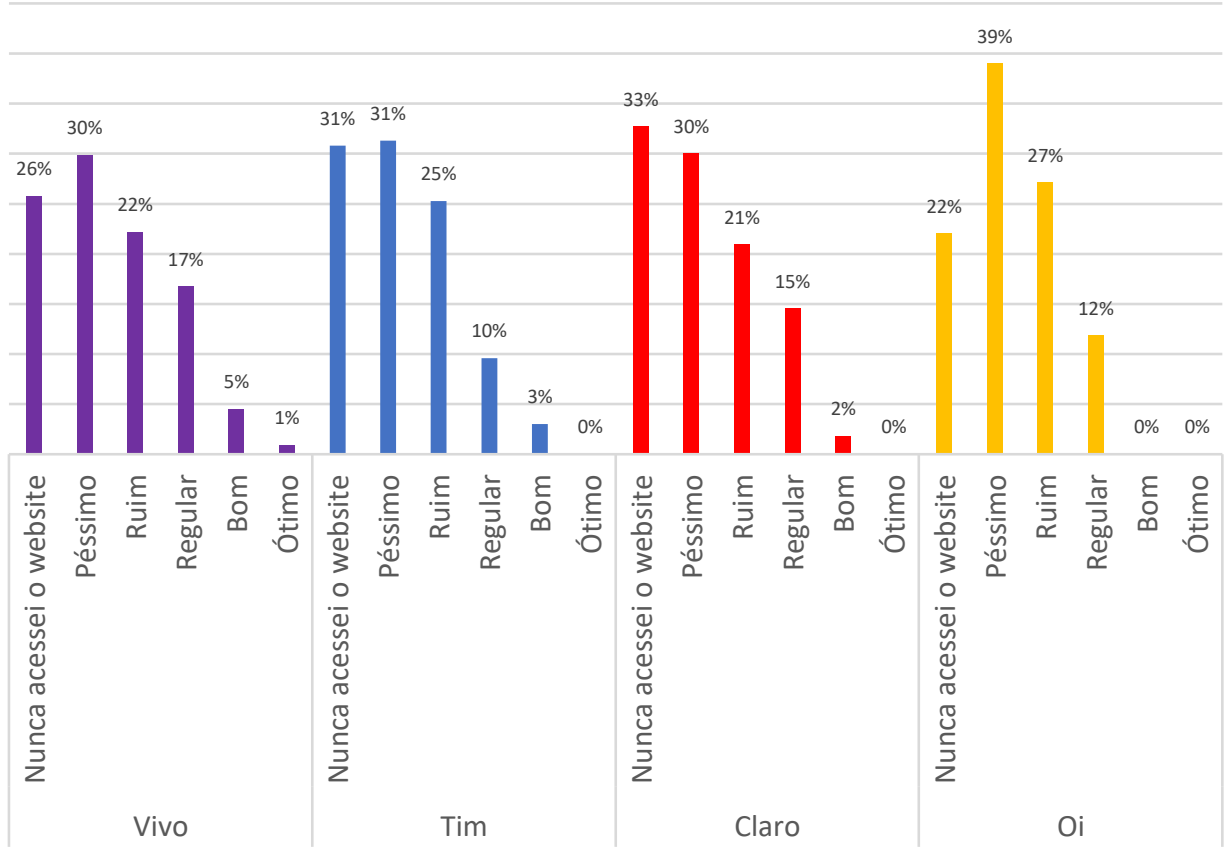

Fonte: Autoria própria (2017)

Conforme expresso pela Figura 8, todas as operadoras de telefonia móvel foram avaliadas por mais da metade de seus usuários como péssimas ou ruins em termos de divulgação de informações acerca dos programas de LR em seus 
websites. Em todos os casos as quantidades de avaliações superaram os que declararam nunca terem acessado os websites das empresas.

Embora as quantidades de respondentes variem bastante entre as operadoras (representando seu Market Share), é possível inferir, após análise, que a Vivo é a melhor avaliada entre as quatro, e a Oi ocupa a última colocação. Os percentuais descritos na Figura 35 fazem referência somente ao número de respondentes de cada operadora, permitindo essa comparação.

Conforme levantado por Domingues, Guarnieri e Streit (2016) a PNRS ainda não foi divulgada suficientemente e, consequentemente, poucas pessoas sabem da sua existência ou de fato a conhecem em profundidade, ou seja, ainda desconhecem o papel das empresas nesse processo e sua respectiva responsabilidade. Assim, é papel do Poder Público e também das empresas, no caso específico desse artigo, de telefonia, divulgar as práticas de logística reversa que têm executado e de que forma estão atendendo a legislação pertinente.

\section{CONSIDERAÇÕES FINAIS}

Os elevados índices de consumo de aparelhos apontam para um cenário, no qual a massificação dos descartes induz a sérios riscos socioambientais. A logística reversa e a Política Nacional de Resíduos Sólidos emergem, então, como possíveis alternativas rumo a sustentabilidade e a redução dos impactos gerados. Entretanto, a simples existência de tais soluções não garante os resultados almejados, sendo necessário o comprometimento de todos os atores envolvidos no processo, sejam esses públicos, privados ou individuais.

Esse trabalho teve por objetivo avaliar sob a ótica dos consumidores e analise dos websites das operadoras se a estrutura de logística reversa para celulares é adequada, conforme exige a PNRS. Para atingir tal objetivo, a avaliação das redes de logística reversa implementadas pelas operadoras de celular ocorreu em duas frentes: sob a ótica dos consumidores e através do mapeamento dos websites oficiais das empresas com base em um codificador proposto por Demajorovic et al. (2012).

Constata-se que, embora as informações de caráter compulsório estejam sendo prestadas (conforme instituído pela PNRS), a qualidade e disseminação dessas ainda está aquém do que pode ser considerado satisfatório. Esse trabalhou também identificou que as operadoras de telefonia móvel, embora cumpram com o que fora determinado pela Política Nacional de Resíduos Sólidos, estão muito aquém do nível desejado em termos de disseminação e qualidade das informações prestadas.

Embora os websites representem apenas um dos diversos canais de divulgação dessas companhias é possível verificar que os próprios consumidores estão insatisfeitos no que diz respeito a essa temática. Além disso, a despriorização em comunicar os meios apropriados de descarte e as consequências dos elevados níveis de consumo podem ser vistas nas diversas campanhas que essas empresas realizam em mídias sociais, na televisão e em outros canais de comunicação em massa. Observa-se, na verdade, uma atitude oposta ao que os estudiosos propõem: vantagens e benefícios para aqueles que querem trocar seu aparelho celular, estimulando, assim, o consumo desenfreado. 
Como limitações podem ser citados: i) 0 instrumento de pesquisa aplicado foi divulgado, majoritariamente, através de canais relacionados a indivíduos que possuem elevados níveis de conhecimento e consciência ambiental, fato esse que pode ser comprovado por $86,2 \%$ da amostra estar cursando ou ter concluído o terceiro grau. Além disso, aproximadamente $73 \%$ dos respondentes ocupam a classe média-alta; ii) A ausência de testes estatísticos para validação das perguntas e escalas aplicadas configura-se como uma limitação nesse estudo. Entretanto, a supressão desses testes é justificada baseando-se nos objetivos da pesquisa, que não propõem a validação das escalas e questionamentos aqui aplicados; iii) O mapeamento dos websites das operadoras de telefonia móvel foi executado por apenas 1 pessoa, não sendo submetido a reanálise ou comparação, embora as técnicas aplicadas objetivam a redução de erros e omissões.

Destaca-se que esse estudo teve como foco as operadoras de telefonia móvel no Brasil, excluindo da análise os comerciantes, fabricantes, dentre outros atores considerados essenciais às diretrizes, princípios e processos estabelecidos pela Política Nacional de Resíduos Sólidos. Ou seja, estudos futuros poderão ser realizados tendo como objetivo o estudo desses elos da cadeia de suprimentos.

Conforme levantado por Domingues, Guarnieri e Streit (2016) a PNRS ainda não foi divulgada suficientemente e, consequentemente, poucas pessoas sabem da sua existência ou de fato a conhecem em profundidade. É necessário que o Governo Federal passe a cobrar uma nova postura das empresas, estimulando-as a destinarem maiores investimentos na divulgação, assimilação e compreensão dos instrumentos e princípios da PNRS. E, claro, a própria esfera pública deve buscar meios de transmitir eficientemente essa importante fonte de conscientização que se configura a PNRS.

\section{AGRADECIMENTOS}

Os autores agradecem ao CNPq - Conselho Nacional de Desenvolvimento Científico e Tecnológico (CNPq) pelo apoio para a realização desta pesquisa. 


\title{
Assessment of the reverse logistics structure of the main Brazilian cellular operators from the perspective of consumers and evaluation of the websites
}

\author{
ABSTRACT
}

The high rates of consumption of cellular handsets have increased the generation of waste in Brazil and the world. In this scenario, Reverse Logistics and the Brazilian Solid Waste Policy emerge as possible solutions that act to reduce the impacts generated by this process. However, the mere existence of such solutions does not guarantee the desired results, and it is necessary the commitment of all the actors involved, public, private or individual. In this article we evaluate the reverse logistics networks implemented by mobile operators in Brazil from the point of view of consumers and also, we evaluate their websites. For this purpose, it was carried out a descriptive and qualitative-quantitative research through survey and documental analysis. The data collection was based on the application of a questionnaire with closed questions in a sample of 596 consumers and also of a coder adapted for the analysis of the websites of the four main cellular operators in Brazil. The results obtained with regard to the structuring of reverse logistics presented results considered unsatisfactory, both from the point of view of the consumer and also related to the information provided related to reverse logistics in their websites. The participation of the actors, based on shared responsibility, as advocated by the PNRS is essential to the effective implementation of reverse logistics.

KEYWORDS: Electrical and electronic waste. National Policy on Solid Waste. Reverse Logistics. 


\section{REFERÊNCIAS}

ABINEE - Associação Brasileira da Indústria Elétrica e Eletrônica. Abinee debate os desafios da logística reversa. 2014. Disponível em: http://www.abinee.org.br/informac/arquivos/infne36.pdf. Acesso em: ago. 2016

ABINEE - Associação Brasileira da Indústria Elétrica e Eletrônica. Green Eletron: uma realidade. 2016. Disponível em: http://www.abinee.org.br/noticias/com38.htm. Acesso em: jun.2017.

ALBUQUERQUE, P. Cálculo do tamanho de amostras: proporções. 2012. Disponivel em: http://pedrounb.blogspot.com.br/2012/05/calculo-do-tamanhode-amostras.html. Acesso em: abr. 2017.

ANATEL - Agência Nacional de Telecomunicações. Telefonia Móvel: Acessos. $2016 . \quad$ Disponível em: http://www.anatel.gov.br/dados/index.php/component/content/article?id=283 Acesso em: jul. 2016.

ANATEL - Agência Nacional de Telecomunicações. Telefonia Móvel: Acessos. 2017. Disponível em: http://www.anatel.gov.br/dados/index.php/component/content/article?id=283 Acesso em: jun. 2017.

ANDRADE, M. M. Introdução à Metodologia do trabalho científico. São Paulo: Atlas, 2010.

BARDIN, L. Análise de Conteúdo. Lisboa: Edições, 1977.

BRAGA FILHO, E. O.; COSTA, B. S.; NETO, P.; CONSTANTINOV, G. N.; WADE, S.; CAETANO, R. M. L. E. M. A.; NASSER F, M. F. R. E. J. S. A. B.; KIECKHOFER, M. M. R. E. A. M.; SOUZA, P. R. P.; BORGES, N.; FAGUNDEZ, P. R. Á.; OLIVEIRA, L. J. Princípios e Objetivos da Nova Política Nacional de Resíduos Sólidos e seus Impactos na Atividade Empresarial. In: Jussara Suzi Nasser Borges Ferreira; Maria de Fátima Ribeiro; Paulo Roberto Pereira de Souza. (Org.). TUTELA JURÍDICA DO MEIO AMBIENTE E DESENVOLVIMENTO. 1ed.São Paulo e Marília 978-85-61: Editora Arte\&Ciência, São Paulo e Editora UNIMAR. Marília-São Paulo, 2010, v. 01, p. 01-219.

BRASIL. Lei 12.305, de 2 de agosto de 2010. Dispõe sobre a Política Nacional de Resíduos Sólidos. Disponível em: http://www.planalto.gov.br/ccivil_03/_ato20072010/2010/lei/l12305.htm. Acesso em: fev. 2017. 
CHAVES, G. L. D.; BATALHA, M. O. Os consumidores valorizam a coleta de embalagens recicláveis? Um estudo de caso da logística reversa em uma rede de hipermercados. Gestão \& Produção, v. 13, n. 3, p. 423-434, 2006. crossref

CHIZZOTTI, A. Pesquisa em ciências humanas e sociais. 8. ed. São Paulo: Cortez, 2006.

DAHER, C. E.; SILVA, E. P. S.; FONSECA A. P. Logística reversa: oportunidade para redução de custos através do gerenciamento da cadeia integrada de valor. 2006. Disponível http://repositorio.unb.br/bitstream/10482/12550/1/ARTIGO_LogisticaReversaOp ortunidade.pdf Acesso em: fev. 2017.

DE BRITO, M. Managing reverse logistics or reverse logistics management? Erasmus Research Institute of Management. PhD thesis. Rotterdam, The Netherlands, Erasmus University: 69, 2003.

DEMAJOROVIC, J.; HUERTAS, M.K.Z.; BOUERES, J.A.; SILVA, A.G.; SOTANO, A.S. Logística reversa: como as empresas comunicam o descarte de baterias e celulares? Rev. adm. empres., São Paulo, v. 52, n. 2, p. 165-178, Apr. 2012.

DEMAJOROVIC, J.; MIGLIANO, J. E. B. Política nacional de resíduos sólidos e suas implicações na cadeia da logística reversa de microcomputadores no Brasil. Gestão \& Regionalidade (Online), v. 29, n. 87, 2013.

DOMINGUES, G. S.; GUARNIERI, P.; STREIT, J. A. C. Princípios e Instrumentos da Política Nacional de Resíduos Sólidos: Demanda da Educação Ambiental para a Logística Reversa. Revista Em Gestão, Inovação e Sustentabilidade. Brasília, v. 2, n. 1, p. 191-216, jun. 2016

DOWLATSHAHI, S. Developing a theory of reverse logistics. Interfaces 30 (3): 143155,2000 . crossref

FLEISCHMANN, M., KIRKKE, H. R., DEKKER, R.; FLAPPER, S. P. (2000). A characterisation of logistics networks for productrecovery. Omega, 28 (6), 653666. crossref

FONTES, R. V.; Logística Reversa e a Responsabilidade das Empresas. In: BRITO, A.C.F.M.; GUARNIERI, P. (org.). Política Nacional de Resíduos Sólidos: implicações legais e gerenciais. Ed. Trigueiro Fontes Advogados. Recife, 2013.

GIL, A. C. Métodos e Técnicas de Pesquisa Social. 5 Ed., São Paulo: Atlas, 2007. 
GUARNIERI, P. 11 Fabricantes de eletroeletrônicos criam a entidade gestora da logística reversa de eletroeletrônicos "Green Eletron" para atender a PNRS. 2016. Disponível em: http://patriciaguarnieri.blogspot.com.br/2016/10/11fabricantes-de-eletroeletronicos.html. Acesso em: jun. 2017.

GUARNIERI, P.; DUTRA, D.; PAGANI, R.; HATAKEYAMA, K.; PILATTI, L. Obtendo competitividade através da logística reversa: estudo de caso em uma madeireira. Journal of Technology Management \&Innovation, v.1, n.4, p.121-130, 2006.

GUARNIERI, P. Logística Reversa e os Impactos da Política Nacional dos Resíduos Sólidos. In: Política Nacional de Resíduos Sólidos: Implicações legais e gerenciais. Recife: Trigueiro Fontes Advogados, 2013, v.

GUARNIERI, P.; E SILVA, L. C.; LEVINO, N. A. Analysis of electronic waste reverse logistics decisions using Strategic Options Development Analysis methodology: A Brazilian case. Journal of Cleaner Production, v. 133, p. 1105-1117, 2016. crossref

HOCH, P. A. A obsolescência programada e os impactos ambientais causados pelo lixo eletrônico: o consumo sustentável e a educação ambiental como alternativas. Seminário Nacional Demandas Sociais e Políticas Públicas na Sociedade Contemporânea, 2016.

IDC. Estudo da IDC mostra recorde nas vendas de smartphones no terceiro trimestre de 2013. 2013. IDC Releases. Disponível em: http://www.idcbrasil.com.br/releases/news.aspx?id=1547 Acesso em: abr. 2017.

IBGE - Instituto Brasileiro de Geografia e Estatística. Pesquisa Nacional por amostra de domicílios. 2013. Disponível em: http://www.ibge.gov.br/home/estatistica/populacao/trabalhoerendimento/pnad 2013/. Acesso em: ago. 2016.

IBGE - Instituto Brasileiro de Geografia e Estatística. Estados@. 2017. Disponível em: http://www.ibge.gov.br/estadosat/perfil.php?sigla=df. Acesso em: jul. 2017.

KROON, L., VRIJENS, G. Returnable containers: an example of reverse logistics. Omega, 30: 325-333, 1995. crossref

LACERDA, L. Logística reversa: uma visão sobre os conceitos básicos e as práticas operacionais. Rio de Janeiro: COPPEAD/UFRJ, p. 6, 2002. 
LEITE, P. B. Logística reversa: meio ambiente e competitividade. São Paulo: Prentice Hall, 2003.

MAGERA, M. Os caminhos do lixo: da obsolescência programada à logística reversa. Campinas, SP: Editora Átomo, 2013.

MIGUEZ, C. E. Logística reversa como solução para o problema do lixo eletrônico: benefícios ambientais e financeiros. São Paulo: Qualitymark, 2010.

MINAYO, M. C. S. Pesquisa social: teoria, método e criatividade. 15. ed. Petrópolis: Vozes, 1994.

MINISTÉRIO DO MEIO AMBIENTE. Logística Reversa. Disponível em: http://www.mma.gov.br/cidades-sustentaveis/residuos-perigosos/logisticareversa. Acesso em: mar. 2017.

MINISTÉRIO DO MEIO AMBIENTE. MMA negocia logística reversa eficiente. 2016. Disponível emhttp://www.mma.gov.br/index.php/comunicacao/agenciainformma?view=blog\&id=1792. Acesso em: mar. 2017.

MOREIRA, I. F.; GUARNIERI, P. Preferência dos consumidores por empresas que implementam práticas de Logística Reversa como meio de fidelização: Estudo Na Industria de Cosméticos Brasileira. Revista Gestão Industrial, v. 12, n. 4, 2016

ONU/BR - Organização das Nações Unidas Brasil. UIT: 3,7 bilhões de pessoas ainda não têm acesso à Internet no mundo. 2016. Disponível em: https://nacoesunidas.org/uit-37-bilhoes-de-pessoas-ainda-nao-tem-acesso-ainternet-no-mundo/. Acesso em: ago. 2016.

RAZZOLINI FILHO, E. R.; BERTÉ, R. O reverso da logística e as questões ambientais no Brasil. Curitiba: Editoralbpex, 2009.

SILVA, E.; MENEZES, E. Metodologia da pesquisa e elaboração da dissertação. Florianópolis, UFSC, 2005.

TELECO - Informação e Serviços de Telecomunicações Ltda. Estatísticas de Celulares no Brasil. 2016. Disponível em: http://www.teleco.com.br/ncel.asp. Acesso em: mai. 2016

TELECO - Informação e Serviços de Telecomunicações Ltda. Estatísticas de Celular no Mundo. 2016. Disponível em: http://www.teleco.com.br/pais/celular.asp. Acesso em: mai. 2016 
TELECO - Informação e Serviços de Telecomunicações Ltda. Operadoras de Celular no Brasil. 2017. Disponível em: http://www.teleco.com.br/opcelular.asp. Acesso em jul. 2017

TRIGO, A. G. M.; ANTUNES, T. R.; BALTER R. S. Uma visão Sustentável dos resíduos eletroeletrônicos de aparelhos de celular. IV Congresso Brasileiro de Gestão Ambiental, Salvador/BA, 25 a 28 set. 2013. Disponível em: http://www.ibeas.org.br/congresso/Trabalhos2013/VII-032.pdf Acesso em: ago. 2016.

UNEP - United Nations Environment Progamme. Recycling from E-waste to resources, ONU, USA, 2009.

UNEP - United Nations Environment Programme. Recycling: From e-waste to resources. 2009. Disponível em: http://www.unep.org/PDF/PressReleases/EWaste_publication_screen_FINALVERSION-sml.pdf. Acesso em: mai. 2016.

Recebido: 01 dez. 2017

Aprovado: 12 dez. 2017

DOI: 10.3895/gi.v13n4.7456

Como citar:

SANTOS, R. H. M.; GUARNIERI, P. Avaliação da estrutura de logística reversa das principais operadoras de celulares brasileiras sob a ótica dos consumidores e avaliação dos websites. R. Gest Industr., Ponta Grossa, v. 13, n. 4, p. 01-25, out./dez. 2017. Disponível

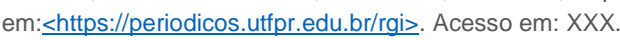

Correspondência:

Ricardo Henrique Moraes Santos

QMSW 5 Lote 2 Bloco D Ap. 130, Setor Sudoeste, Brasília, Distrito Federal, Brasil.

Direito autoral: Este artigo está licenciado sob os termos da Licença Creative Commons-Atribuição

4.0 Internacional. 